Bond University

Research Repository

\title{
Understanding the Challenges, Yet Focusing on the Successes: An Investigation into Indigenous University Students' Academic Success
}

Lydster, Cameron; Murray, Jason

Published in:

Australian Journal of Indigenous Education

DOI:

10.1017/jie.2018.15

Licence:

CC BY-NC-ND

Link to output in Bond University research repository.

Recommended citation(APA):

Lydster, C., \& Murray, J. (2019). Understanding the Challenges, Yet Focusing on the Successes: An Investigation into Indigenous University Students' Academic Success. Australian Journal of Indigenous Education, 48(2), 107-118. https://doi.org/10.1017/jie.2018.15

\section{General rights}

Copyright and moral rights for the publications made accessible in the public portal are retained by the authors and/or other copyright owners and it is a condition of accessing publications that users recognise and abide by the legal requirements associated with these rights.

For more information, or if you believe that this document breaches copyright, please contact the Bond University research repository coordinator 


\title{
Understanding the challenges, yet focusing on the successes: An investigation into Indigenous university students' academic success
}

\author{
Cameron Lydster and Jason Murray \\ Bond University, Queensland, Australia
}

This paper reports on experiences of Indigenous students and staff involved in Bond Indigenous Tutoring (BIT). It aimed to gain insight regarding topics including challenges faced by Indigenous students, why some students discontinued their studies, and concepts of success at university. Findings revealed the main challenges included the transition from secondary to tertiary education and not being prepared academically. BIT staff identified family responsibilities and being dislocated from kinship networks as challenges, while students stated these were factors explaining why Indigenous students discontinued their studies. A whole of university approach was found to be required to effectively support Indigenous students. Success was defined as more than Grade Point Average, as it entailed being able to enjoy future endeavours. This paper contributes to the evidence that tuition programmes and Indigenous centres at university are key contributors to success, and it is argued that such success must become the norm as opposed to the exception.

Key Words: Indigenous students, higher education, retention, challenges, success, ITAS-TT.

\section{Indigenous students in Australian higher education}

Throughout the literature on Indigenous higher education in Australia, a common theme is that Indigenous people are underrepresented from both a student and staff perspective (White, Frawley, \& Thi Kim Anh, 2013). Awareness of the issue has increased (Patton, Lee Hong, Lampert, Burnett, \& Anderson, 2012), yet rates of participation and retention among Indigenous university students remain low (Rochecouste et al., 2016). Aboriginal and Torres Strait Islander student participation within universities continues to be 'significantly below the population parity rate', despite efforts to address this situation (Wilks \& Wilson, 2015, p. 17). Thus, there exists a critical need to increase enrolments of Indigenous students within higher education to reach socialjustice goals nationwide (Barney, 2016).

While access to tertiary education has been identified as a significant issue, so too have the success and retention rates of Indigenous students. Described as 'volatile' in 2007 (Bradley, Noonan, Nugent, \& Scales, 2008, p. 32), in 2014, the retention rate for Aboriginal and Torres Strait Islander students was $71.2 \%$. Although up from $69 \%$ in 2009 , it was still considerably below the 2014 rate for 'all domestic students' of 79.9\% (Universities Australia, 2017, p. 25). Clearly, too many Indigenous students dis- continue their studies without having achieved a degree or award (Bradley et al., 2008), and such failure at university may contribute to reduced self-esteem, potentially leading to social exclusion. It is argued that 'failed models' in the com- 
munity may discourage other Indigenous people from commencing study, having a negative flow on effect for generations (Koramannil, 2016, p. A-91). Consequently, responding to the issue of retention and providing Indigenous students with the opportunities to succeed academically are paramount.

Much of the literature talks about issues with gaining entry and, subsequently, retention of Aboriginal and Tor- res Strait Islander students. Another important discussion topic is, therefore, success in tertiary education, yet it is important to examine what success means. Although there is a dearth of literature specifically examining students' definitions of success in higher education, broad definitions are commonly presented (Herbert, 2003; Whatman, McLaughlin, Willsteed, Tyhuis, \& Beetson, 2008). Pechenkina (2014, p. 37) discovered that while universities equate success with completion of degrees, success for Indigenous students involves utilising their studies 'as means to achieve their life goals'. Similarly, Whatman et al. (2008) found that obtaining 'good grades' was just one of myriad definitions of success, with developing life skills, reaching personal study goals and achieving desired employment being key factors. Stewart (2009), who employed conversation circles and interviews, deter- mined that Indigenous students' perceptions of what constitutes success in higher education were closely connected to achieving a study-life balance: being able to meet the demands of studies and responsibilities to family and community.

\section{Challenges Faced by Indigenous Students in Higher Education}

The decision to commence university studies is not simple; various considerations influence an Indigenous person's decision to commence and continue studying, including social, cultural, economic and political factors (Andersen, Bunda, \& Walker, 2008). As identified by Patton et al. (2012), it is imperative to establish what specific factors impede Indigenous students' enrolment in and completion of university degree programmes. One of the most commonly cited barriers to tertiary education for Indigenous students is financial barriers (Asmar, Page, \& Radloff, 2011; Pechenkina, Kowal, \& Paradies, 2011) and flow on effects, including having to prioritise employment over study (James, Krause, \& Jennings, 2010), and limited access to learning resources (Rochecouste et al., 2016). Additional barriers include, but are not limited to, family and community pressures and lack of support and/or necessary academic skills.

Being first in family to undertake tertiary studies is a further commonly cited barrier. For a number of Indigenous students, participation within higher education is a 'cross-cultural experience' and, therefore, a 'daunting' one, particularly when there are limited role models to provide assistance (Patton et al., 2012, p. 10). Students who are first in their family to engage in higher education may require financial and academic support, as well as assistance with managing family and community responsibilities (Rochecouste et al., 2016). For students who are the first in family to attend university, those around them are often sceptical or at least unsure of what studying at university entails and leads to (Stewart, 2009). Some Indigenous community members see the institution as a hostile or unsafe environment for Indigenous students, some view them as abandoning their cultures and taking on a 'white lifestyle'. This may lead to students feeling they lack strong support networks, which, often, is precisely what is required (Rochecouste et al., 2016).

A related challenge is students' 'newness' to academia. DiGregorio, Farrington, and Page (2000) identified that unfamiliarity with tertiary education, their peers and study in general, was a common challenge for Indigenous students. The study found that participants felt overwhelmed by the new environment, being bereft of social networks, and especially being unaware of where or how support could be sought. When first commencing tertiary studies, many Indigenous students, like their non- Indigenous counterparts, report feelings of being overwhelmed and scared (Oliver, Rochecouste, \& Grote, 2013). Such newness to academia can re- 
sult in students having difficulty adapting to new academic environments (Rochecouste et al., 2016).

A further obstacle is a lack of requisite academic skills. Academic skills are seen as a 'stumbling block' by some Indigenous students, due to factors including limited opportunities in prior studies and having transitioned from employment into study (Patton et al., 2012). Such academic skills or literacies include dealing with academic discourse, particularly discipline specific language, and having required literacy and numeracy skills. Thus, discovering what initiatives are effective in terms of assisting students to overcome such challenges and contributing positively to Indigenous student retention and completion is imperative (Barney, 2016).

\section{Initiatives Taken to Address Barriers to Academic Success}

To address the education gap between Indigenous and non-Indigenous people, it is a requirement of the Australian government that each university endeavours to advance the goals of the National Aboriginal and Tor- res Strait Islander Policy, and thus funding, taking many forms, is provided to support Indigenous students at university (Wilks \& Wilson, 2015). In turn, most institutions adopt multifaceted approaches to supporting Indigenous learners (Oliver et al., 2013).

Studies examining support for Indigenous students have found the importance of providing dedicated spaces on campuses (e.g. Rochecouste et al., 2016). Pechenkina et al. (2011) determined that Indigenous centres are associated with higher student completion rates. Such centres clearly offer opportunities for Indigenous students to build relationships and be supported by mentors and/or peers. Rochecouste et al. (2016) noted centres' ability to enable students to adapt to academic culture, while Morgan (2001) found they provided culturally safe environments in which students could seek guidance and support. Additionally, one of the key support mechanisms put in place by the Department of Education, Employment and Workplace Relations (DEEWR) and now over- seen by the Prime Minister and Cabinet was the additional tutoring assistance scheme, the Indigenous Tutorial Assistance Scheme (Tertiary Tuition) or ITAS-TT. Under the scheme, Indigenous students at Australian tertiary institutions were eligible for up to 2 hours targeted tuition per subject, per week throughout the semester of a formal program. An additional provision for exam preparation of 5 hours per subject was also provided with institutions themselves managing the tuition programmes.

Throughout the literature on support programmes for Indigenous students, a common theme is that ITAS-TT played an important role in retaining and helping students succeed at university (Pechenkina, 2014; Wilks \& Wilson, 2015). Behrendt, Larkin, Griew, and Kelly (2012) noted that ITAS-TT assisted regarding the development of Indigenous learners' academic literacies and comprehension of subject content. In a qualitative study, Patton et al. (2012, p. 33) found that the majority of student participants identified ITAS-TT as being 'central to their success'. Furthermore, the Group of Eight Universities Australia (Go8, 2015, paras. 14-15) described ITAS-TT as 'a successful and well-regarded program, despite some admit- ted imperfections', including its administration being burdensome, stressing that it was 'one of the most important factors in supporting Indigenous students' successful participation in higher education'. Unfortunately, there is a dearth of literature reporting in detail on the efficacy of support programmes, such as ITAS-TT (Oliver et al., 2013). However, one study that did specifically examine ITASTT's efficacy was conducted by Whatman et al. (2008), finding that the participation rates of Indigenous students and the perceived 'success' of the programme at Queensland University of Technology were directly linked.

\section{The Bond University Context}

Bond University inhabits a unique position as a nonprofit private university and recognises the 
important role universities play in supporting students' personal and professional aspirations. In 2015, 2.8\% of the University's commencing domestic students identified as Aboriginal or Torres Strait Islander (Department of Education and Training, 2016). As reported in The Australian, the retention rate of Indigenous students at Bond University in 2015 was significantly higher than the national average rate of 71\% in 2013-2014 (Ferguson, 2016).

Since 2012, Bond University has invested significantly in the creation of the Nyombil Indigenous Support Centre, tuition fee scholarships, living bursaries and outreach programmes. Consequently, the cohort has increased substantially from 19 students in 2010 to 70 in January 2017, the highest number of Indigenous students enrolled at the University to date (Bond University, 2017b). It is believed various factors have contributed to the significant growth of Indigenous cohorts, such as the retention rate, a new purpose built Indigenous Centre and a scholarship programme supported by both the University and the wider community.

TABLE 1

Snapshot of Results of Indigenous Students at Bond University Between 2013-2016 (Bond University, 2017a)

\begin{tabular}{lrrrr}
\hline & 2013 & 2014 & 2015 & 2016 \\
\hline Number of students & 10 & 23 & 31 & 45 \\
Subjects attempted & 17 & 62 & 113 & 158 \\
Subjects passed & 13 & 50 & 95 & 142 \\
Subjects failed & 4 & 12 & 18 & 16 \\
Subject pass \% & $76 \%$ & $80 \%$ & $84 \%$ & $90 \%$ \\
\hline
\end{tabular}

\section{Bond Indigenous Tutoring (BIT)}

The Nyombil Centre is fully integrated with other university support services and manages the Bond Indigenous Tutoring (BIT) programme, formerly referred to as ITAS-TT. The federally funded tutoring programme commenced at Bond University in October 2013 and assisted 13 students over a seven-week period. Before receiving the tutoring, students who participated in the programme had a $52 \%$ pass rate in their subjects. After participating in the ITAS-TT program for seven weeks, the cohort pass rate increased to $68 \%$.

The number of Indigenous students receiving tutoring has increased each year in accordance with increased enrolments, with all eligible commencing students being allocated a Support Officer (SO) in their first semester. In addition, the subject pass rate of the cohort receiving tuition has increased each year. The positive impact of the tutoring programme is demonstrated in Table 1 above.

In addition, Figure 1 on the subsequent page outlines the outcomes achieved by the 45 Indigenous students who received tutoring across three semesters in 2016.

Six of the eight students who graduated in the first graduation ceremony of 2017 received tutoring in 2016. Of the seven undergraduates who graduated in 2016, four received tutoring during their enrolment. Consequently, one aim of the present study was to investigate whether BIT contributed to both retention and completion rates at Bond University.

\section{The Current Study}

To gain a deeper understanding about BIT and broader topics relevant to determine best practices for supporting Aboriginal and Torres Strait Islander students, the present study sought insights from both student recipients and instructors of the tutoring scheme.

Based on the literature reviewed, the following research questions were posed: 
1. What challenges are faced by Indigenous students, and how can such challenges be overcome?

2. Why do Indigenous students discontinue their studies?

3. How is success at university defined? What skills or attributes do students need to have or develop to be successful?

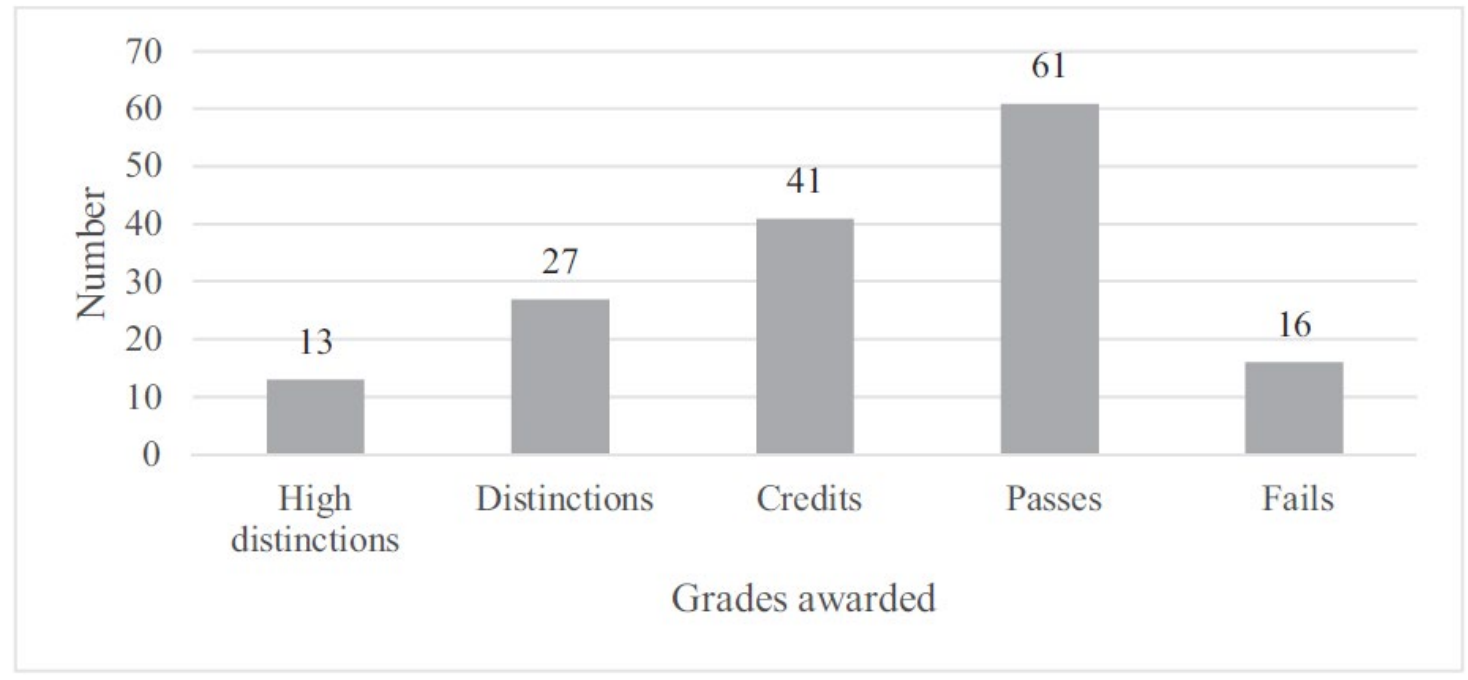

FIGURE 1

Outcomes achieved in terms of overall grades of 45 ATSI students over three semesters in 2016 at Bond University (Bond University, 2017a).

\section{Method}

The current study employed a case study methodology, using a qualitative research design involving four inter- views, two with BIT SOs who had both tutored at Bond University and other Australian universities, one with a student recipient of BIT and one current SO (the 'student/tutor') who previously received ITAS-TT tuition at two Australian universities (Bond University and another university). Additionally, three focus groups were facilitated; one focus group was conducted with eight student recipients of the tutoring, while two focus groups involved SOs, four and two in each group, respectively. Each interview and focus group lasted approximately 60 minutes.

Qualitative design has been utilised widely in Indigenous Australian education studies (e.g. Asmar \& Page, 2017; Harrison, Tridgett, \& Page, 2016). Interviews were chosen as they are one of the most common methods of obtaining insight into social practices, and because personal perceptions, opinions, beliefs and values are often best comprehended via interview (Richards, 2003). Additionally, focus groups involving controlled group discussion in small groups of approximately 1 hour were employed, as they allow researchers to 'get closer to the thoughts and experiences of smaller and more specific segments of society' (Morgan, 2002, p. 142).

Ethics was obtained from Bond University's Human Research Ethics Committee (RO 15809) and each stage of the research conformed with the National Health and Medical Research Council's Guidelines for Ethical Con- duct in Aboriginal and Torres Strait Islander Health Research (NHMRC, 2003). As noted by DiGregorio et al. (2000), research involving Aboriginal and Torres Strait Islander peoples and their communities needs to bene- fit them. This necessity formed the basis of our research methods and objectives; hence, respect for each participant, the Nyombil Indigenous Centre and the tutoring programme (BIT) were foundations of the current study. The study was designed in consultation with the University's Indigenous Cultural SO and 
upon completion of the paper was reviewed by an Indigenous academic in the Faculty of Law. Please note that both researchers are non-Indigenous.

Participants in the current study were recruited by emailing all students and SOs involved in BIT separately and inviting participation in a focus group on the 'Indigenous Tutoring Scheme'. Four participants, including two SOs, one student and one student/tutor were approached by the primary researcher to participate, as each had been involved in the tuition programme for at least 3 years and three of the four had been involved in ITAS-TT at more than one institution. It was determined that these four would, therefore, provide detailed insight into their own experiences and the experiences of others. Each student participant was provided lunch and a cinema voucher for participating in the focus group, which was conducted in week 9 of the third trimester in 2016. The student and the student/tutor who were interviewed were provided with a cinema voucher, while the SOs were remunerated for their time.

Bond University's Indigenous Cultural SO was present at the focus groups and was listed as a contact on the explanatory statement in case students experienced dis- tress at any stage of participating in the study. Due to potential risk of power dependency, the primary researcher, who does not work in the Nyombil Centre, conducted all interviews and focus groups. Both interviews and focus groups were recorded, and a research assistant transcribed the audio, with each participant's data de-identified. The transcriptions were then analysed using NVIVO 11 to identify common themes.

\section{Results}

Participants were categorised as student recipients of BIT, SOs who taught as part of the scheme and one student/tutor who had received tutoring, but at the time of the study was employed as an SO. In total, nine students, eight SOs and one student/tutor participated. Each student identified as being Indigenous as did two SOs and the student/tutor. All students were enrolled in under- graduate programmes.

\section{Identified Challenges}

The transition from high school to university was stated to be a significant challenge by both SOs and students. One student recalled, 'the challenges I faced were just kind of keeping up with it. Uni's different to school'. When asked about the 'step up' from high school to university, the student stated, 'you have no one to like guide you through; you're just kind of expected to have a certain level of knowledge and know how to independently work and how to be effective'. The student/tutor had a similar experience, noting that the transition was conspicuous, especially when tasked with his/her first assignment:

I remember the first assignment I ever got was like a philosophy assignment, and just not even knowing where to start ... I was so stressed in my undergrad because of that difference from high school and no one really warns you about it.

Associated with the transition from secondary to tertiary level was not being academically prepared. This involved not being equipped with academic literacies, such as critical reading, numeracy, and, particularly, academic writing skills. One SO stated that students who had 'come out of a non-academic background were simply not aware of the requirements of university, their course, and they were unprepared for the level of work, which was required'.

Not being sufficiently equipped with the academic literacies to participate fully at university was also seen as a common challenge from the students' perspectives. The student/tutor identified navigating academic texts, such as journal articles, as challenging, particularly in the first semester. Academic writing was also identified by numerous students as a challenge, one stated: 
I remember the first time I had a session with my tutor, I was like "I don't even know how to start it". "I haven't written anything in that long", I didn't even know how to start a sentence, you know. And I used to love writing in school, but I hadn't done it in so long, so that was my biggest challenge I think, just relearning how to write academically again.

The aforementioned challenges led to serious consequences, as one SO described, 'it became difficult to actually get them to engage into the work. I believe that they were trying to do the work. But they continued to have such poor, poor outcomes that they became depressed'. Another SO acknowledged that the initial culture shock faced by some students in the first semester was quite disheartening:

They were just really unengaged. University was like this huge scary place and they had no idea, like they weren't going to class and it wasn't because they didn't care necessarily, it was just because, like class was scary and it was all overwhelming.

Notably, family commitments were seen as a common challenge among SOs. One SO acknowledged, "what I saw was when you have families outside, for example from Cairns or from Torres Strait Islands, or WA, they were going back and forth'. Another, who described the situation of a student from a remote community recalled, 'these kinds of family situations or concerns, or emergencies that cropped up were so regular that the studies became sort of disjointed and fragmented'. Although students did not identify family commitments as a challenge, when asked why Indigenous students discontinue their studies (research question 2), they noted having faced 'lots of pressure' both internal and external, including from family and community.

\section{How Challenges Were Overcome}

The two most common responses to the question of how students overcame challenges were the support provided by BIT and the University's Indigenous unit, the Nyombil Centre. Regarding BIT, SOs and students noted the value of personalised, one-to-one assistance once rapport was established. Benefits of the scheme included assisting in the development of academic literacies, particularly writing skills. For one SO, this was accomplished via joint construction of texts with students and using an explicit teaching model, in which the SO presented exemplars and showed what was required.

Assisting in the development of organisational and time management skills was another key benefit of the tutoring. For instance, students and SOs often set goals and planned the semester, as one SO explained:

I say to them "you know when your assignments are due and it's Week 1 right now, so this is our goals" ... I think if you have goals and you help them set them and they become really visual, they're more likely to reach those goals.

It was clear the students appreciated that the tuition encompassed both general academic skills and content specific knowledge. General academic skills were seen as particularly valuable in students' first semester to make the transition from high school or employment to university much smoother, one student recalled, 'I like it, it helped a lot, especially when I was starting out. It gave me an idea of actually how to do things at uni, how to prepare for tutorials, like what the most effective study methods are'. However, being paired with SOs who had knowledge of the subject area was considered most beneficial. The in-depth content knowledge such SOs possessed allowed them to effectively explain concepts, 'especially after you read it and you still don't get it, so they're good at just making it simple', as one student described.

A final benefit of the tuition scheme, noted by the SOs, was that it made students responsible for 
their studies. One SO explained, 'even though it's not written in black and white, they were expected to perform at a certain level. So they have that sense of responsibility and, obviously the ITAS tutors, if the tutor is really enthusiastic, they would push them'. This was seen by another $\mathrm{SO}$ as being beneficial for students who, based on prior results, were considered at risk of failing, "with these particular students, I really kept on the ball and every time we met, it would be like "what's going on with that assignment? What's going on with this one?"

Furthermore, students frequently described the Nyombil Centre as instrumental in overcoming challenges. The 'sense of community' established in the centre allowed students to feel at home and receive various types of support. One student surmised, 'one of the things I love about the Centre, it's like a big family and a support network, so you can come here and, you know, pretty much everyone is there to support you'. The peer support afforded within the Nyombil Centre was described as being beneficial for all who utilised it, with students regularly helping each other. One student recalled a recent experience:

Yesterday, I had one of the psych students come and help me. Because I know everyone so well, I'm like "oh, can you help me with this?" And so really, you can call on 10 people even if your [BIT] tutor's not here, because everyone's so well connected, and relationships are formed, and so you don't have to be embarrassed.

The centre was described as a place where students could relax and de-stress. This was particularly valuable for students who were away from family and lacked support networks. One student reflected:

I find there's less pressure. I can perform better where there's less pressure . . . I go to the library, everyone's stressed . . . and there's just kind of a competitive vibe. While here it's just like you can relax, also have chats, or put your headphones on and just work.

Further, academic staff at Bond University were described by students as being supportive in overcoming challenges. One student described academics' approachability, recalling:

I've sent like heaps of emails, and they all respond, and then, even in this last sem, I just literally dropped by the office to see if one of them was free We sat there for half an hour because he kept just trying to explain stuff to me. I would ask questions. A couple of days ago, $[\mathrm{I}]$ met up with another one of my lecturers, I think we sat there for an hour and she was just happy to talk about everything, go through everything, make sure I understood it all.

Both groups of participants also noted that additional assistance in overcoming university challenges came from the various support services at Bond University. These services included Student Learning Support (SLS), the University's Academic Language and Learning (ALL) unit; the Career Development Centre; Library Services and Student Counsellors. One student noted, 'I just got advice from everyone'. Both students and SOs were aware of the majority of support services available to students, and often these services were provided before students had sought it, as one SO explained:

They [students] were prepared to get a lot of assistance from the tutoring and from the other tutor groups which they were involved and engaged in, and from Student Learning Support ... they had a lot of resources that they can draw on. I found that they were being offered quite a lot of support as well. People were actually hunting them down and thrusting support upon them. 
Overall, it was agreed that having a variety of sources for support, as long as students felt they were approachable, led to positive outcomes.

\section{Why do Indigenous Students Discontinue their Studies?}

Among the student participants, feelings of homesickness, isolation and a disconnect from kinship networks and community were identified as the most common reason for Indigenous students discontinuing. One student suggested, 'I think that home-sickness is a big thing ... and I get homesick every week'. Another agreed stating, 'especially for people straight out of high school too and they're used to living with their families and stuff, because sometimes I just want to feel like I'm at home'. Connected to this was the feeling of being isolated. One student expressed, 'sometimes Aboriginal people from, they might not be from an Aboriginal community, but everyone they're connected to is Aboriginal, so your teachers might be white at school and stuff but you don't have a relationship'. A related point was the feeling of disconnect from community. One student acknowledged:

I think one of the challenges that was faced by me and my mum when she studied is that where we're from, I don't know if it's like this in other tribes or communities, but they almost looked down on us because we wanted better, and they were like, "well, you think you're too good now, like oh you're doing this." Like we got a lot of that. And whenever, you know, I go down and visit and spend time with them, like I was almost, didn't want to talk about that I was doing well, because I felt like they didn't accept me anymore.

This disconnect from kinship networks was expressed by another student, who stated, 'when I started jurisprudence, it took me a few months to tell my brothers and sisters that I had got into law, because it was, the gap was too large, from my life to their life'.

Finally, both students and SOs agreed that the first semester was critical in terms of ensuring Indigenous students felt comfortable, had the confidence to achieve their goals and were aware of the support mechanisms around them, including who they could talk to if problems arose. The student/tutor claimed, 'that first semester is probably the primary one where they either feel welcome and they stay or they drop out'.

Notably, only one SO mentioned financial barriers as reasons why Indigenous students ceased studying. In addition, of the students involved in the study, only the student/tutor expressed financial concerns as either a challenge for students or a reason as to why Indigenous students discontinued their studies.

\section{Definitions of Success at University}

Consistently, participants identified success at university as not only concerning obtaining a high Grade Point Average (GPA), but setting oneself up for the future, leading to positive outcomes for future employment or gaining admission to further education. The most common response was surmised by one SO:

One would want a student to excel in their grades academically ... then go for a higher GPA, but I personally would think ... university is not the end of life. I think you have to use university as a bridge in between your school life and your professional life, whatever it may be.

This idea of using university as a bridge to future endeavours was echoed among participants. One student described success succinctly as, 'to get what they've always dreamed of and start the course of where they want to end up'. This meant that success at university was unique for 
each individual, involving setting and achieving personal goals. One SO argued, 'I think for me it's about achieving goals that are personal to you and that you think you want to achieve'.

Additionally, competence was identified as a key element of success at tertiary level. The student/tutor stated this was the case for him/her but also noted that it had evolved over time:

I think if you had of asked me that during my honours or during my undergraduate degree, it would be getting the marks that you need to get into Masters or to get you into honours ... Oh, it took me a while to get out of that headset. I actually really noticed that this semester. That I get a mark and I'm like "yeah great", but I go straight to the feedback to see, like you know that that mark is just a number. Now I'm more concerned with competence ... I think it's a lot healthier to become fixated on improving yourself and your abilities and not fixated on some number.

Encouragingly, several students felt they were successful due to being accepted as part of an academic community and the networks already established (e.g. personal success is connection and community), being able to balance social and study life, and most significantly, con- tributing to changing stereotypes. One student explained:

I think that for me success is overcoming that like, “you're Indigenous, you don't go to uni", sort of stereotype. For me, I think that's success and I think telling other people, like other kids because where I'm from, I'm from Cherbourg, it's like this little Aboriginal mission that no one really gets out of, and for me that's just like, so big, so I think for me it's just like telling other kids and my cousins and everyone at home that they can do it too. That for me is success.

\section{Required Skills/Attributes for Success}

Participants were asked what skills or attributes were required or needed to be developed by Indigenous students for them to succeed as per their definitions. Responses to this question varied; however, common themes included having the motivation and determination to achieve one's end goal. One student argued, 'you've got to be fully committed. You have to really want what you're here for, because it's so much hard work'. Another student concurred:

I think you have to have your own personal drive and desire to do it, because if you don't have that then what are your goals? And, you know, how are you going to get there? I think the reason why I've continued is because I have such a drive to, you know, to achieve it.

Connected to motivation was having a level of passion for one's chosen degree programme, as noted by one SO, 'I think the biggest one is to be passionate about what it is that you're studying'.

Confidence was another common theme. This included students being equipped with confidence in their abilities to succeed and to say 'this is what I want to do, and I know I can do it'. The student/tutor explained that confidence was a key ingredient concerning university success for Indigenous students in particular:

Because that's how you can go and talk to teachers to go clarify stuff. I think it helps you bounce back from a bad mark in those earlier years, you know when you do just pass, you need to be confident in yourself that you can take on that feedback and use it to help your next assignment. I think confidence is a big one for Indigenous students because there is that general stigma around the lower education and all that sort of stuff. 
Having a connection to culture was also seen as imperative by the students. One student explained:

I reckon connection to culture is a big one. Before I came to Bond, I had no connection to culture whatsoever, since like my parents were separated and I lived with my dad. It was my mum's side that's Aboriginal, and I just had no education whatsoever about my own culture and being able to come to Bond gave me that cultural connection which I've been looking for and it also like encouraged me to keep going.

The student continued to explain that:

You want to do well, and you want to make a difference and I think, you know, part of the culture is community and connection and supporting one another, so even in terms of that kind of stuff, just coming back to your roots and understanding, well, you're not alone, it's not just about you, like you can help everyone around you and I think like a really good quality for success is understanding everyone's in it together.

\section{Discussion}

This study aimed to investigate the experiences of Indigenous students at Bond University by gaining insight from both Indigenous students receiving tutoring from the federally funded Indigenous tutoring scheme (formerly referred to as ITAS-TT, currently BIT) and SOs. The initial research question regarded the challenges faced by Indigenous students at tertiary level and how these could be overcome. A related question was why, in participants' opinions, Indigenous students chose to discontinue their studies. The final research question was how students and SOs defined the concept of success at university and what attributes were required to be successful.

Regarding the specific challenges faced by Indigenous students, the common themes were the transition from secondary to tertiary education and not being academically prepared, which included lacking requisite academic literacies, such as academic writing skills. Furthermore, the SOs identified family commitments as a challenge, yet students only talked about family responsibilities when describing reasons for Indigenous students discontinuing their studies. Financial challenges were only referred to twice (once by an SO and once by the student/tutor); this is notable, as a significant proportion of the literature refers to financial struggles as being an impediment to university commencement, retention and success (Asmar et al., 2011; Rochecouste et al., 2016). However, the themes that were identified in this study are well documented in the literature (DiGregorio et al., 2000; Patton et al., 2012; Pechenkina et al., 2011; Rochecouste et al., 2016). Clearly, studying at university can be overwhelming for any student (Barney, 2016). It is important to note that many of the challenges identified in the current study are not unique to Indigenous Australians, a point acknowledged by several SOs and students.

The most common responses to how challenges were overcome included the support in the form of BIT; the Nyombil Centre, including the staff and students who created the centre's supportive environment; the University's academic staff and other support units including SLS, Library services and the CDC. This finding is encouraging, as Behrendt et al. (2012) recommended that a plethora of mechanisms be employed to effectively support Indigenous learners at university. Additionally, Andersen et al. (2008) argued that the entire university must be commit- ted in a practical and philosophical sense for higher rates of graduation among Indigenous students to be realised. This means that the support mechanisms in place cannot be carried by only one unit, rather it is the role of many within an institution to ensure students feel supported. 
The current study found that BIT plays a crucial role in assisting students with overcoming challenges, particularly early on in their degrees when challenges are most apparent. Students described how valuable personalised support was with outcomes including the development of academic literacies and organisational skills, as well as enhanced learning experiences. This finding contributes to the paucity of literature assessing the efficacy of ITAS-TT or similar programmes. To the authors' knowledge, to date, only one study (Whatman et al., 2008) has investigated ITAS-TT's role in Indigenous students' stories of academic success and it is believed that in order for such programmes to continue, more evidence into their efficacy is required.

Additionally, the Nyombil Centre was identified as playing a critical role in a variety of areas. This is perhaps unsurprising as several researchers, including Andersen et al. (2008), pointed to the imperative roles played by Indigenous centres. Di Gregrio et al. (2000) emphasised the importance of providing culturally safe and positive learning environments, as is the aim of the Nyombil Centre. Success among Indigenous students depends on them being provided spaces that not only recognise their experiences and knowledge brought with them into the tertiary environment but also support their engagement within the institution (Syron \& McLaughlin, 2010). Asmar and Page (2017) detailed that some universities are, unfortunately, making the decision to close their Indigenous centres; thus, it is perhaps timely that this study provides support that decisions to close such imperative resources are ill-advised.

The most common responses to the question of why Indigenous students discontinued their studies included feelings of homesickness, isolation and disconnection from kinship networks. Without downplaying the significance of homesickness and feelings of isolation, the latter point, a potential disconnect from family and community is notable. It is frequently posited in the literature that there is a need for mutually supportive relationships to exist between families and schools, and this relationship is considered one of the factors which under- pin successful, formal education (Chenhall, Holmes, Lea, Senior, \& Wegner, 2011; Mason, Perry, \& Dockett, 2006; Pechenkina \& Anderson, 2011; Trudgett, Page, Bodkin- Andrews, Franklin, \& Whittaker, 2017). This necessity for family involvement in Indigenous student education has been documented in Australia and abroad, for instance, in Canada (Malatest, 2002). Thus, there is a clear need to strengthen relationships between students, kinship and educational institutions while identifying ways of minimising the impacts homesickness and feelings of isolation have on Indigenous students.

Regarding Indigenous student retention, Bond University has been most fortunate, as it appears to 'buck the trends' observed by many Australian universities. However, much like the difficulty in measuring ALL Learning Advisors' contribution to students' development of academic literacies (Chanock, 2007; Lydster \& Brown, 2017), it is difficult to pinpoint the factors and to what extent they have contributed to the positive outcomes for Indigenous students at the University. It is believed that due to the plethora of support mechanisms (e.g. approachable academic staff, BIT and the Nyombil Centre, SLS, CDC and Library Services), students, in particular, Indigenous students, at Bond University feel adequately supported. As noted by Asmar et al. (2011), students' perceptions of university support mechanisms are linked directly to their decisions to continue or discontinue their studies. If students do not perceive support, there is an increased chance they will be lost to the tertiary system. For now, it is believed that Aboriginal and Torres Strait Islander students at Bond University indeed feel supported.

Concerning definitions of success at university, both groups' concepts were far more meaningful than simply GPA. Both defined university success as being a stepping stone to future, enjoyable endeavours. This meant that a student's successful completion (i.e. passing) of a degree programme's subjects, and therefore grades, were necessary; however, success was far more than academic scores. Students noticed their conceptions of success at university had evolved over time to focus more on their competencies. This is notable, as it demonstrates students' aware- ness of their knowledge/skill development and potential employability. Further, students 
viewed their participation in higher education as a success in itself. This is in line with findings that success entails the ability to meet the demands of academia and responsibilities to family (Stewart, 2009), while realising personal and professional aspirations (Rochecouste et al., 2016) and setting oneself up for the future (Whatman et al., 2008). The student not- ing that he/she was already successful, as his/her continued participation in academia was breaking the 'you're Indigenous, you don't go to uni' stereotype was, perhaps, as inspiring as the student participant in Pechinkina's (2017, p. 15) study who stated quite aptly, 'I want to succeed to prove the bastards wrong'.

The most common responses to what skills and/or attributes were required to be successful were motivation, confidence and having a connection to culture and community. Regarding motivation, the first-year experience study conducted by James et al. (2010) demonstrated that Indigenous students displayed high motivation and commitment to their studies; however, a range of pressures are often faced. Such pressures may affect students' motivation, and it is believed one such factor is confidence, or lack thereof.

It is apparent confidence plays a key role for all university students. Involvement in prior studies, including secondary schooling and university preparation pro- grammes, assists in the development of Indigenous students' confidence in their academic abilities and pursuits (Rochecouste et al., 2016). Stewart (2009) reported that students 'survived' tertiary education due to their own resilience and personal belief. As highlighted by Patton et al. (2012), successful learners persevere, retake subjects and/or seek help. Students who lack resiliency or assertive- ness often are embarrassed to seek help, become demoralised and may discontinue their studies. It is imperative that university support mechanisms aim to distil confidence in students' abilities, focusing on what knowledges they bring with them, while assisting in developing lifelong skills. As demonstrated by Morgan (2001), support services' focus on building confidence led to positive outcomes for all involved, as students who had higher self-esteem were more inclined to possess higher motivation, achieve higher GPAs and less inclined to discontinue studying.

Student participants and the student/tutor realised the importance of being connected to culture and that they were important role models. One student expressed that his/her connection to culture had been developed whilst studying and defined this realisation as a motivator for continued hard work, a realisation consistent in the literature (DiGregorio et al., 2000). This is a point worth further investigation, as even though it was defined as a necessary attribute for success and a motivator by different students, it may also be placing additional pressure on students. Unfortunately, very often when one student discontinues his or her studies, many more may see that student's experience as a reason not to participate in furthering their education.

\section{Conclusion}

This study has added further evidence to the extant literature that it is imperative Indigenous students feel supported by various areas within institutions and that confidence for all students at university is enhanced. Tertiary institutes differ in how they deliver support to Indigenous students (Patton et al., 2012) and, like any support mechanism, one size does not fit all. It is believed that this case study of how Bond University employs a whole of university approach to supporting Indigenous students demonstrates the need for continued funding into such endeavours. It is crucial that the mechanisms that have been put in place and proven to be successful are not adversely affected by changes to government or institutional policy.

As argued by Devlin (2009), it is time to focus on success and what works regarding improving Indigenous equity, and it is believed this paper has made some contribution to this area. There is an opportunity to act on what has been found and champion successful students as role models for future cohorts, so that Indigenous student success becomes the norm. Rather than claiming the success of Indigenous students as the University's success in order to 'window-dress' 
(Pechenkina, 2017), it is hoped that studies such as the current paper will assist stakeholders in discovering a more complete understanding of academic success for Aboriginal and Torres Strait Islander students. It is imperative we refrain from resting on our laurels.

\section{Acknowledgments}

First and foremost, we would like to acknowledge the people of the Yugambeh language, upon whose ancestral lands Bond University now stands. Many thanks to Narelle Urquhart for advising us on the study and providing support for students involved. Thank you to Deputy Vice Chancellor (Students \& Support Services) Alan Finch and Assistant Professor Narelle Bedford for providing feedback on our paper. Thank you also to Dr Sue Whatman and Dr Katya Pechenkina for pointing us in the right direction. Special thanks to the Indigenous students and Support Officers for providing us with such valuable insight.

\section{References}

Andersen, C., Bunda, T., \& Walter, M. (2008). Indigenous higher education: The role of universities in releasing the potential. The Australian Journal of Indigenous Education, 37, 18. https://doi.org/10.1017/S1326011100016033.

Asmar, C., \& Page, S. (2017). Pigeonholed, peripheral or pioneering? Findings from a national study of Indigenous Australian academics in the disciplines. Studies in Higher Education, 1-13. doi:10.1080/03075079.2017.1281240.

Asmar, C., Page, S., \& Radloff, A. (2011). Dispelling myths: Indigenous students' engagement with university. Australian Survey of Student Engagement, 10, 1-16. Retrieved from: http://research.acer.edu. au/cgi/viewcontent.cgi?article=1001\&context=ausse.

Barney, K. (2016). Listening to and learning from the experiences of Aboriginal and Torres Strait Islander students to facilitate success. Student Success, 7, 1-11. doi: 10.5204/ssj.v7i1.317.

Behrendt, L., Larkin, S., Griew, R., \& Kelly, P. (2012). Review of higher education access and outcomes for Aboriginal and Torres Strait Islander people: Final report. Canberra: DEEWR. Retrieved from https://www. education.gov.au/review-higher-educationaccess-and- outcomes-aboriginal-and-torres-strait-islander-people.

Bond University. (2017a). Aboriginal and Torres Strait Islander students' results at Bond University. Strategy, Systems and People. Unpublished data.

Bond University. (2017b). Indigenous initiatives. Retrieved May 3, 2017 from https://bond.edu.au/ alumni-partners/community/indigenous-initiatives.

Bradley, D., Noonan, P., Nugent, H., \& Scales, B. (2008). Review of Australian higher education: Final report. Canberra: DEEWR. Retrieved from https://www.mq. edu.au/ data/assets/pdf_file/0013/135310/bradley_review_of_australian_higher_education.pdf.

Chanock, K. (2007). Valuing individual consultations as input into other modes of teaching. Journal of Academic Language \& Learning, 1(1), A1-A9. Retrieved from http://www.journal.aall.org.au/index.php/jall/article/ view/1/4.

Chenhall, R.D., Holmes, C., Lea, T., Senior, K., \& Wegner, A. (2011). Parent-school engagement: Exploring the concept of 'invisible' Indigenous parents in three north Australian school communities. Darwin, Australia: The Northern Institute. Retrieved from http://ro.uow.edu.au/sspapers/1458/. 
Department of Education and Training. (2016). Table 6.2: Commencing and all Indigenous students by state, higher education institution and gender, full year 2015. Retrieved from https://docs.education.gov.au/node/41721.

Devlin, M. (2009). Indigenous higher education student equity: Focusing on what works. The Australian Journal of Indigenous Education, 38, 1-8. https://doi.org/10.1375/S1326011100000533.

DiGregorio, K.D., Farrington, S., \& Page, S. (2000). Listening to our students: Understanding the factors that affect Aboriginal and Torres Strait Islander students' academic success. Higher Education Research \& Development, 19(3), 297-309. doi:10.1080/758484344.

Ferguson, R. (2016, July 6). Bond University tops field in retaining Indigenous students. The Australian. Retrieved from http://www.theaustralian.com. au/highereducation/bond-university-tops-field-in- retaining-indigenous-students/news-story/ $33374514083994 f 02033 \mathrm{fc} 4 \mathrm{ecf} 10 \mathrm{ac} 71$.

Group of Eight Universities Australia. (2015, May 4). Go8 Submission to the inquiry into Common- wealth Indigenous Advancement Strategy tendering processes. Retrieved from https://go8.edu.au/ publication/go8-submission-inquiry-commonwealth- indigenous-advancement-strategy-tendering-processes.

Harrison, N., Trudgett, M., \& Page, S. (2016). The dissertation examination: Identifying critical factors in the success of Indigenous Australian doctoral students. Assessment \& Evaluation in Higher Education, 42(1), 115-127. doi:10.1080/02602938.2015.1085488.

Herbert, H. J. (2003). Is success a matter of choice? Exploring Indigenous Australian notions of success within the con- text of the Australian university. (Doctoral thesis, Royal Melbourne Institute of Technology, Australia). Retrieved from https://researchbank.rmit.edu.au/view/rmit:11437.

James, R., Krause, K., \& Jennings, C. (2010). The first year experience in Australian universities: Findings from 1994 to 2009. Centre for the Study of Higher Education, The University of Melbourne. Retrieved from http:// melbourne-cshe.unimelb.edu.au/ data/assets/pdf_file/0003/1706403/FYE_Report 1994 to_2009-1.pdf.

Koramannil, G. (2016). Looking for the invisible: The case of EALD Indigenous students in higher education. Journal of Academic Language and Learning, 10, A87-A100. Retrieved from http://journal.aall. org.au/index.php/jall/article/viewArticle/402.

Lydster, C., \& Brown, S. (2017). The value of post-entry language assessment (PELA): Outcomes from a first semester undergraduate subject. Journal of Academic Language Learning, 11(1), A39-A57. Retrieved from http://journal.aall.org.au/index.php/jall/article/view/434.

Malatest, R. A. (2002). Parent and education engagement partnership project: A discussion paper. Retrieved from https://bccpac.bc.ca/upload/2016/05/parent and education engagement partnership project-_a discu. pdf.

Mason, T., Perry, B., \& Dockett, S. (2006). Transition to school for Aboriginal children: What's it take? Childhood Education, 82(3), 139-144. Retrieved from https://researchoutput.csu.edu.au/ws/portalfiles/portal/ 8739328.

Morgan, D. (2001). Indigenous education: Factors affecting students' decisions to continue to work or withdraw from Tertiary Studies at Flinders University. International education 
Journal, 2(4), 233-239. Retrieved from https://ehlt.flinders.edu.au/education/iej/articles/v2n4/ MORGAN/PAPER.PDF.

Morgan, D. (2002). Focus group interviewing. In J. Gubrium \& J. Holstein (Eds.), Handbook of interview research: Con-text \& method (pp. 141-159). Thousand Oaks, CA: Sage Publications.

National Health \& Medical Research Council. (2003). Values and ethics: Guidelines for ethical consideration in Aboriginal and Torres Strait Islander health research. Retrieved from https://www.nhmrc.gov.au/_files_nhmrc/publications/attachments/e52.pdf.

Oliver, R., Rochecouste, J., \& Grote, E. (2013). The transition of Aboriginal and Torres Strait Islander students into higher education. Office for Learning \& Teaching. Retrieved from http://www.olt.gov.au/ project-transition-aboriginal-and-torres-strait-islanderstudents-higher-education-2011.

Patton, W.A., Lee Hong, A., Lampert, J., Burnett, B.M., \& Anderson, J. (2012). Report into the retention and graduation of Aboriginal and Torres Strait Islander students enrolled in initial teacher education. More Aboriginal and Torres Strait Islander Teachers Initiative, University of South Australia. Retrieved from http://www.matsiti.edu.au/acde-2012report.

Pechenkina, E. (2014). Being successful. Becoming successful: An ethnography of Indigenous students at an Australian university. (Unpublished Doctoral thesis, The University of Melbourne, Australia).

Pechenkina, E. (2017). Persevering, educating and influencing a change: A case study of Australian Aboriginal and Torres Strait Islander narratives of aca- demic success. Critical Studies in Education. doi: 10.1080/17508487.2017.1309327.

Pechenkina, E., \& Anderson, I. (2011). Background paper on Indigenous Australian higher education: Trends, initiatives and policy implications. Canberra: DEEWR. Retrieved from https://www.dese.gov.au/access-and-participation/resources/background-paperindigenous-australian-higher-education-trends-initiatives-and-policy-implications

Pechenkina, E., Kowal, E., \& Paradies, Y. (2011). Indigenous Australian students' participation rates in higher education: Exploring the role of universities. Australian Journal of Indigenous Education, 40, 59-68. doi:10.1375/ajie.40.59.

Richards, K. (2003). Qualitative inquiry in TESOL. Basingstoke: Palgrave, Macmillan.

Rochecouste, J., Oliver, R., Bennell, D., Anderson, R., Cooper, I., \& Forrest, S. (2016). Teaching Australian Aboriginal higher education students: What should universities do? Studies in Higher Education, 1-19. doi:10.1080/03075079.2015.1134474.

Stewart, J. (2009). Indigenous narratives of success: Exploring conversation groups as research methodology with Aboriginal and Torres Strait Islander students at the University of Queensland. (Unpublished Doctoral thesis, The University of Queensland, Australia).

Syron, M., \& McLaughlin, J.M. (2010). Indigenous knowledges: Informing and supporting Indigenous students during their first year at university. Proceedings of the 13th Pacific Rim First Year in Higher Education Conference 2010, QUT Publications, 1-11. Retrieved from http://eprints.qut.edu.au/42353/.

Trudgett, M., Page, S., Bodkin-Andrews, G., Franklin, C., \& Whittaker, A. (2017). Another brick in the wall? Parent perceptions of school educational experiences of Indigenous 
Australian children. In M. Walter, L. L. Mar- tin, \& G. Bodkin (Eds.), Indigenous children growing up strong: A longitudinal study of Aboriginal and Torres Strait Islander families (pp. 233-258). London: Palgrave Macmillan.

Universities Australia. (2017). Indigenous strategy 2017-2020. Retrieved from https://www.universitiesaustralia. edu.au/Media-and-Events/mediareleases/Universities- unveil-indigenous-participation-targets\#.WazRP7IjFhE.

Whatman, S., McLaughlin, J., Willsteed, S., Tyhuis, A., \& Beetson, S. (2008). Quality and efficacy of the Indigenous tutorial assistance scheme (ITAS) for university students. Australian Journal of Indigenous Education, 37, 118-130. doi:10.1375/S1326011100000454.

White, N., Frawley, J., \& Thi Kim Anh, D. (2013). Good practice report: Innovative Indigenous teaching and learning. Office for Learning \& Teaching. Retrieved from http://www.olt.gov.au/resource-good-practice-report- innovative-indigenous-teachingand-learning-2013.

Wilks, J., \& Wilson, K. (2015). A profile of the Aboriginal and Torres Strait Islander higher education student population. Australian Universities' Review, 57(2), 17-30. Retrieved from http://www.aur.org.au/current/ contents. 